\title{
ANALISIS PENDAPATAN AGROINDUSTRI OPAK KETAN SERTA KONTRIBUSINYA TERHADAP TOTAL PENDAPATAN RUMAH TANGGA PERAJIN \\ (Suatu kasus pada Kelurahan Kota Baru Kecamatan Cibereum Kota Tasikmalaya)
}

\author{
ANALYSIS OF GLUOTINUS OPAQUE AGRO-INDUSTRY INCOME AND ITS \\ CONTRIBUTION TO THE TOTAL HOUSEHOLD INCOME OF CRAFSTMEN \\ (A case in Kota Baru Subdistrict, Cibereum District, Tasikmalaya City)
}

\author{
RIZA RIZKI ${ }^{1 *}$, IWAN SETIAWAN ${ }^{2}$, MUHAMMAD NURDIN YUSUF $^{3}$ \\ ${ }^{1}$ Fakultas Pertanian Universitas Galuh \\ ${ }^{2}$ Fakultas Pertanian Universitas Padjadjaran \\ E-mail: rizarzq@gmail.com
}

\begin{abstract}
ABSTRAK
Agroindustri merupakan penggerak utama perkembangan sektor pertanian yang diharapkan dapat menciptakan kondisi yang saling mendukung industri maju, serta berperan dalam penciptaan lapangan kerja baru, dan perbaikan distribusi pendapatan sehingga melalui pengembangan pengolahan produk pertanian dapat memberikan kontribusi yang besar terhadap perekonomian di Indonesia. Tujuan penelitian ini adalah untuk mengetahui 1) Besarnya biaya yang di keluarkan yang di keluarkan oleh perajin opak ketan di Kelurahan Kota Baru Kecamatan Cibeureum Kota Tasikmalaya, 2) Besarnya pendapatan agroindustri opak ketan per bulan di Kelurahan Kota Baru Kecamatan Cibereum Kota Tasikmalaya, 3) Kontribusi pendapatan agroindustri opak ketan per bulan terhadap pendapatan keluarga di Kelurahan KotaBaru Kecamatan Cibereum Kota Tasikmalaya. Metode yang digunakan dalam penelitian ini adalah survey di Kelurahan Kotabaru. Sedangkan pengolahan data menggunakan analisis biaya, penerimaaan, pendapatan dan kontribusi pendapatan agroindustri opak ketan. Hasil dari penelitian menunjukan: 1) Besarnya Rata-rata biaya total yang dikeluarkan oleh pengrajin opak ketan di Kelurahan Kotabaru Kecamatan Cibereum pada agroindustri opak ketan per satu kali proses produksi adalah Rp 850.827.-; 2) Rata-rata pendapatan total yang diperoleh pengrajin opak ketan di Kelurahan Kotabaru Kecamatan Cibereum pada agroindustri opak ketan per satu kali proses produksi adalah $\mathrm{Rp} 607.506,-; 3)$ Kontribusi pendapatan rata-rata responden dari agroindustri opak ketan adalah $78,02 \%(\operatorname{Rp} 4.860 .049,-)$.
\end{abstract}

Kata Kunci : pendapatan, kontribusi pendapatan,agroindustri, opak ketan

\begin{abstract}
Agro-industry is the main driving force for the development of the agricultural sector which is expected to create mutually supportive conditions for advanced industries, as well as play a role in creating new jobs and improving income distribution so that through the development of agricultural product processing it can make a major contribution to the economy in Indonesia. The purpose of this study was to determine 1) The amount of costs incurred by glutinous opak craftsmen in Kota Baru Village, Cibeureum District, Tasikmalaya City, 2) The amount of opak glutinous agro-industry income per month in Kota Baru Subdistrict, Cibereum District, Tasikmalaya City, 3) Contribution the income of glutinous opak agroindustry per month towards family income in KotaBaru Village, Cibereum District, Tasikmalaya City. The method used in this research is a survey in Kotabaru Village. Meanwhile, data processing uses cost analysis, revenue, income and contribution of glutinous opaque agro-industry. The results of the study showed: 1) The amount of average total cost incurred by glutinous opak craftsmen in Kotabaru Village, Cibereum District in the glutinous opaque agroindustry per one production process is IDR 850,827.-; 2) The average total income obtained by opak glutinous producers in Kotabaru Village, Cibereum District, in the glutinous opak agro-industry per
\end{abstract}


one production process is Rp. 607,506; 3) Contribution of respondent's average income from glutinous opak agro-industry is $78.02 \%$ (IDR 4,860,049, -).

Kewords: income, revenue contribution, agroindustry, glutinous opak.

\section{PENDAHULUAN}

Kehadiran agroindustri ditengah kehidupan masyarakat perdesaan dikerjakan dengan memanfaatkan waktu luang di luar usahatani. Di daerah perdesaan, pembangunan industri kecil, termasuk industri rumah tangga, yang bersifat informal dan tradisional diarahkan untuk memperluas lapangan kerja dan kesempatan berusaha, menumbuhkan kemampuan dan kemandirian berusaha serta meningkatkan pendapatan pengusaha kecil dan perajin. Adanya agroindustri sebagai kerja sampingan diharapkan mampu memberikan tambahan pendapatan (Suprapto, 2008).

Salah satu hasil pertanian yang dapat dimanfaatkan hasil nya sebagai suatu produk olahan yaitu beras ketan. Beras ketan (Oryza Sativa L.var.Glutinosa) merupakan salah satu varietas padi yang termasuk dalam family Gramina. Butir beras ketan sebagian besar terdiri dari zat pati (sekitar $80-85$ persen) yang terdapat dalam endosperma yang tersusun oleh granula-granula pati yang berukurn 3-10 milimikro. Beras ketan juga mengandung vitamin terutama dalam bagian aleuron), mineral dan air. Beras ketan banyak terdapat di Indonesia dengan jumlah produksi sekitar 42.000 ton per tahun. Ketan atau beras ketan memiliki ciri yaitu tidak transparan, berbau khas, seluruh atau hampir seluruh patinya merupakan amilopektin. Ketan hampir seluruhnya di dominasi oleh amilopektin sehingga sangat lekat.

Agroindustri berbahan baku ketan merupakan salah satu sumber pendapatan bagi sebagian besar masyarakat yang tinggal diperdesaan dan berkontribusi penting bagi pendapatan rumah tangga. Salah satunya adalah industri opak ketan. Kota Tasikmalaya merupakan wilayah yang memiliki industri opak ketan yang terkenal di Jawa Barat. Produk ini dibuat dari beras ketan yang diolah dengan cara dipanggang di atas api.

Menurut data Dinas Perindustrian dan UMKM Tasikmalaya, nilai produksi opak ketan di Kota Taikmalaya bisa mencapai Rp 1.355.084.000,-./ tahunnya. Hal tersebur didasari karena banyak nya peminat terhadap makanan opak ketan.Menurut data dari Dinas Perindustrian, Perdagangan, Koperasi dan UMKM Kota Tasikmalaya (2019), terdapat 28 unit usaha Opak Ketan yang tersebar di 
Kota Tasikmalaya. Kecamatan Cibereum merupakan penghasil opak ketan tertinggi mencapai nilai produksi yaitu Rp1.062.840.000,. Sedangkan Kelurahan Kotabaru memiliki perajin terbanyak di Kecamatan Cibereum sebanyak 6 orang perajin.

Opak ketan banyak diusahakan di Kelurahan Kota Baru dalam bentuk agroindustri skala rumah tangga dengan ciri pengusahaan yang turun temurun dan pengolahannya masih menggunakan tenaga manual atau tenaga kerja manusia baik tenaga kerja dari dalam keluarga, maupun tenaga kerja dari luar keluarga. Walaupun demikian untuk tetap mempertahankan cita rasa opak ketan yang dihasilkan tidak berubah. Maka pengolahan masih mempertahankan cara-cara tradisioanal oleh karena industri ini berupa industri rumah tangga, maka biasanya tidak ada pencatatan mengenai besarnya biaya yang dikeluarkan, penerimaan diperoleh serta pendapatan yg diterima. Hal ini menyebabkan pengrajin opak ketan tidak mengetahui keseluruhan biaya yang dikeluarkan dan pendapatan bersih yang diperoleh.

Usaha opak ketan ini tidak terlepas dari tantangan dan hambatan baik dari segi permodalan, sumber daya manusia, manajemen dan faktor-faktor produksi, musim maupun persaingan yang cukup ketat serta rendahnya pendapatan keluarga yang diterima. Ada beberapa masyarakat yang menjadikan usaha ini sebagai pekerjaan pokok namun ada pula menjadikan sebagai pekerjaan sampingan tergantung seberapa besarnya pendapatan opak ketan berkontribusi terhadap pendapatan rumah tangga untuk memenuhi kebutuhan hidup.

Menurut

Simanulang

(2006), pendapatan rumah tangga dialokasikan untuk memenuhi kebutuhan konsumsi. Hal tersebut tergantung bagaimana setiap individu mampu mengalokasikan sumber pendapatan yang diterima. Menurut Mosher (1995), hal yang paling penting dari kesejahteraan adalah pendapatan, sebab beberapa aspek dari kesejahteraan rumah tangga tergantung pada tingkat pendapatan.

Pemenuhan kebutuhan dibatasi oleh pendapatan rumah tangga yang dimiliki, terutama bagi yang berpendapatan rendah. Semakin tinggi besarnya pendapatan rumah tangga maka persentase pendapatan untuk pangan akan semakin berkurang. Dengan kata lain, apabila terjadi peningkatan pendapatan dan peningkatan tersebut tidak merubah pola konsumsi maka rumah tangga tersebut sejahtera. Sebaliknya, apabila peningkatan 
pendapatan rumah tangga dapat merubah pola konsumsi maka rumah tangga tersebut tidak sejahtera. Berdasarkan alasan tersebut maka sangat menarik dilakukan kajian tentang "Analisis Pendapatan Agroindustri Opak Ketan serta Kontribusinya Terhadap Pendapatan Rumah Tangga Pengrajin di Kelurahan Kota Baru Kecamatan Cibereum Kota Tasikmalaya".

\section{METODE PENELITIAN}

Jenis Penelitian

Jenis penelitian yang digunakan dalam penelitian ini adalah penelitian kualitatif dan kuantitatif dengan metode survei yang mengambil kasus di Kelurahan Kotabaru Kecamatan Cibereum Kota Tasikmalaya Jawa Barat.

\section{Teknik Pengumpulan Data}

Data yang digunakan dalam penelitian ini adalah data sekunder dan primer. Data primer diperoleh dari wawancara langsung dengan objek penelitian sedangkan data sekunder diperoleh dari instansi yang terkait seperti Dinas Perindustrian Perdagangan dan UMKM, studi kepustakaan yang menyangkut keadaan umum daerah penelitian opak ketan di Kelurahan Kotabaru Kecamatan Cibereum Kota Tasikmalaya.

\section{Teknik Penarikan Sampel}

Teknik sampling yang digunakan yaitu purposive sampling dengan beberapa pertimbangan yaitu responden berada pada usia produktif dan agroindustri opak ketan yang sudah memiliki izin usaha. Maka dari itu, sampel yang diambil dalam penelitian ini sebanyak 6 perajin opak ketan di Kelurahan Kota Baru.

\section{Rancangan Analisis Data}

1. Analisis Biaya

a. Biaya total (Total Cost) diperoleh dengan cara menjumlahkan biaya tetap total (Total Fixed Cost) dengan rumus (Suratiyah, 2006):

$$
\mathrm{TC}=\mathrm{TFC}+\mathrm{TVC}
$$

Keterangan :

TC = Total Cost (biaya total)

TFC $=$ Total Fixed Cost (biaya tetap total)

TVC $=$ Total Variabel Cost (biaya variabel total)

\section{Analisis Penerimaan}

Secara umum perhitungan penerimaan total (Total Revenue) adalah jumlah produksi dikalikan dengan harga jual satuan produksi, dinyatakan dengan rumus sebagai berikut: (Suratiyah.2006):

$$
\mathrm{T} \mathrm{R}=\mathrm{Y} . \mathrm{Hy}
$$

Keterangan :

$$
\begin{aligned}
\mathrm{TR} & =\text { Penerimaan Total }(\mathrm{Rp}) \\
\mathrm{Y} & =\text { Jumlah produksi yang } \\
& \text { dihasilkan }(\mathrm{Kg})
\end{aligned}
$$

Hy = Harga jual produksi $(\mathrm{Rp} / \mathrm{Kg})$ 
3. Analisis Pendapatan

Pendapatan adalah penerimaan total (Total Revenue) dikurangi dengan biaya total (Total Cost) digunakan rumus sebagai berikut (Suritiyah,2006):

$\pi=\mathrm{TR}-\mathrm{TC}$

Keterangan :

$$
\begin{aligned}
\pi & =\text { Pendapatan } \\
\mathrm{TR} & =\text { Penerimaan total }(\mathrm{Rp}) \\
\mathrm{TC} & =\text { Biaya total }(\mathrm{Rp})
\end{aligned}
$$

4. Kontribusi Pendapatan

Kontribusi pendapatan bertujuan untuk memberikan sumbangan atau pemasukan terhadap perkumpulan atau suatu usaha yang dilakukan. Kontribusi pendapatan agroindustri opak ketan terhadap pendapatan rumah tangga pengrajin opak ketan dapat dihitung dengan rumus (Akbar,2012):

$$
\mathrm{K}=\mathrm{A} / \mathrm{B} \times 100 \%
$$

Keterangan :

$\mathrm{K}=$ Kontribusi suatu usaha (\%)

$\mathrm{A}=$ Pendapatan dari suatu usaha (Rp)

$\mathrm{B}=$ Total Pendapatan $(\mathrm{Rp})$

\section{HASIL DAN PEMBAHASAN \\ Identitas Responden}

Jumlah responden yang terlibat dalam penelitian ini adalah 6 orang perajin yang berasal dari beberapa RT di wilayah Kelurahan Kotabaru. Data yang digunakan berupa umur, pendidikan, pengalaman berusaha dan jumlah tanggungan keluarga. Untuk lebih jelasnya dapat dilihat pada

\begin{tabular}{|c|c|c|c|}
\hline No. & Uraian & Jumlah (Orang) & Presntase (\%) \\
\hline \multirow[t]{4}{*}{1} & Umur (tahun) & & \\
\hline & $49-54$ & 3 & 50 \\
\hline & $55-64$ & 3 & 50 \\
\hline & Total & 6 & 100 \\
\hline \multirow[t]{3}{*}{2} & Pendidikan & & \\
\hline & SD & 4 & 66,7 \\
\hline & SMP & 2 & 33,3 \\
\hline & Total & 6 & 100 \\
\hline \multirow[t]{5}{*}{3} & Pengalaman (Tahun) & & \\
\hline & $7-12$ & 2 & 33,3 \\
\hline & $13-19$ & 3 & 50 \\
\hline & $20-25$ & 1 & 16,67 \\
\hline & $\begin{array}{c}\text { Total } \\
\end{array}$ & 6 & 100 \\
\hline \multirow[t]{4}{*}{4} & Tanggungan Keluarga(orang) & & \\
\hline & $1-3$ & 1 & 16,67 \\
\hline & $>3$ & 5 & 83,33 \\
\hline & Total & 6 & 100 \\
\hline
\end{tabular}
tabel 1 .

Tabel 1. Perajin Opak Ketan Menurut Umur, Pendidikan, Tanggungan Keluarga, dan Pengalaman Berusaha di Kelurahan Kotabaru Kecamatan Cibereum. 
Umur seluruh responden (100\%) berada pada usia produktif dengan kisaran umur antara 44 sampai dengan 62 tahun. Hal tersebut dapat mempengaruhi kemampuan berfikir dan berusaha lebih maksimal.

Tingkat pendidikan mempunyai peranan yang penting bagi seseorang dala menjalankan kegiatan usahanya. Semakin tinggi tingkat pendidikan seseorang maka semakin tinggi pula respon terhadap teknolgi baud an cara berpikir. Rata-rata pendidikan responden hanya tamatan Seklah Dasar (SD) atau sederajat.

Pengalaman berusaha opak sangatlah beragam, dan sebagian besar memiliki pengalaman berusaha diatas 10 tahun, hal ini menunjukkan pengrajin opak ketan sudah paham akan berusaha agroindustri opak ketan.

Tanggungan keluarga pengrajin opak pada penelitian ini terdiri dari istri, anak, dan anggota keluarga lainnya yang menjadi tanggungan kepala keluarga. Jumlah tanggungan keluarga responden sebagian besar menanggung lebih dari 3 anggota keluarga. Dengan jumlah tanggungan yang besar maka pengrajin akan memiliki tenaga kerja dalam keluarga yang lebih besar pula

\section{Analisis Biaya Agroindustri Opak Ketan \\ a. Biaya}

Biaya yang dikeluarkan oleh perajin opak ketan di Kelurahan Kotabaru dapat dilihat pada Tabel 2.

Tabel 2. Rincian Rata-Rata Biaya Total Agroindustri Opak Ketan per Satu Kali Proses Produksi.

\begin{tabular}{llr}
\hline No & \multicolumn{1}{c}{ Jenis Biaya } & Besarnya Biaya (Rp) \\
\hline 1 & Biaya Tetap & \\
& PBB & 137 \\
& Penyusutan Alat & 25.057 \\
& Bunga Modal & 12,60 \\
& $\quad$ Total Biaya Tetap & $\mathbf{2 5 . 2 0 6}$ \\
\hline 2 & Biaya Variabel & 585.708 \\
\hline & Sarana Produksi & 241.500 \\
& Tenaga Kerja & 413 \\
& Bunga Modal Variabel & 825.621 \\
\hline & $\quad$ Total Biaya Varabel & $\mathbf{8 5 0 . 8 2 7}$ \\
\hline 3 & Biaya Total & \\
\hline
\end{tabular}

Biaya total yang dihitung dalam penelitian ini meliputi biaya total tetap 
ditambah biaya total variabel. Besarnya biaya tetap yang dikeluarkan masingmasing responden berbeda-beda. Biaya penyusutan alat dipengaruhi oleh jenis dan banyaknya alat yang digunakan dan dimiliki pengrajin dalam usaha opak ketan. Jenis alat yang digunakan meliputi: langseng, panci, pengaduk, alat tumbuk, saringan, loyang, tampir, ebeg, oven, alat cetak dan kompor.

\section{Analisis Penerimaan Agroindustri Opak Ketan per Satu Kali Proses Produksi.}

Penerimaan merupakan nilai produksi yang diperoleh dari produk total dikalikan dengan harga jual yang berlaku. Rata -rata biaya produksi opak ketan yang dikeluarkan perajin dalam satu kali proses produksi Rp 850.827,-, sedangkan rata-rata produksi opak ketan di Kelurahan Kotabaru per satu kali proses produksi yaitu sebanyak 29,17 kilogram. Untuk harga jual opak ketan yaitu sebesar Rp 50.000,- per kilogram. Jadi rata-rata besarnya penerimaan yang diperoleh perajin opak ketan adalah Rp 1.458.333,untuk satu kali proses produksi.

\section{Analisis Pendapatan Agroindustri Opak Ketan. \\ Pendapatan atau keuntungan} merupakan selisih antara penerimaan dan biaya total. Rata-rata biaya total yang dikeluarkan perajin opak ketan dalam satu kali proses produksi yaitu sebesar $\mathrm{Rp}$ 850.827,-. Rata-rata penerimaan sebesar Rp 1.458.333,-, sehingga perajin opak ketan rata-rata mendapatkan keuntungan sebesar Rp 607.506,- per satu kali produksi. Dalam satu kali produksi menghabiskan waktu 3 sampai 4 hari, jadi dalam sebulan pengrajin opak ketan memproduksi sebanyak 8 kali dan dalam setahun memproduksi sebanyak 96 kali. Dengan pendapatan rata-rata per bulan yaitu sebesar Rp 4.860.049,-. Hal tersebut dapat melebihi angka Upah Minimum Regional Tasimalaya maupun Jawa Barat.

\section{Pendapatan Total Keluarga Perajin Opak Ketan di Kelurahan Kotabaru Kecamatan Cibereum}

Pendapatan total keluarga merupakan jumlah penghasilan dari seluruh anggota rumah tangga yang digunakan untuk memenuhi kebutuhan bersama dalam rumah tangga. Pendapatan perajin opak ketan tidak hanya berasal dari agroindustri opak ketan, melainkan perajin mempunyai pendapatan lain baik dari sektor jasa, sektor perdagangan maupun sektor pertanian. Hasil penelitian menunjukan bahwa pendapatan total keluarga terkecil yaitu Rp 2.813.099,- dan pendapatan total keluarga tertinggi sebesar Rp 9.095.223,-. Untuk rata-rata total pendapatan keluarga per bulan adalah sebesar Rp 5.871.716, 


\section{Kontribusi Pendapatan Agroindustri Opak Ketan Terhadap Pendapatan Rumah Tangga Perajin}

Kontribusi pendapatan merupakan sumbangan yang diberikan dari suatu usaha terhadap seluruh pendapatan keluarga. Kontribusi pendapatan agroindustri opak ketan dikonversikan dalam satu bulan. Kontribusi pendapatan $78 \%$ (artinya bahwa usaha agorindusti opak ketan dapat memberikan rata - rata kontribusi sebesar 78 persen atau setara dengan Rp 4.860.049,- per bulan. Dengan demikian usaha opak ketan memberikan sumbangan yang besar bagi perajin, sehingga usaha agroindustri opak ketan ini harus dipertahankan dan ditingkatkan, baik dari segi sarana produksi maupun tenaga kerja untuk menunjang perekonomian masyarakat di Kelurahan Kotabaru Kecamatan Cibereum semakin lebih baik.

\section{KESIMPULAN DAN SARAN}

Berdasarkan hasil dan pembahasan, maka dapat ditarik kesimpulan sebagai berikut:

1. Besarnya rata-rata biaya total yang dikeluarkan oleh pengrajin opak ketan di Kelurahan Kotabaru Kecamatan Cibereum pada agroindustri opak ketan per satu kali proses produksi adalah Rp 850.827.--

2. Rata-rata pendapatan total yang diperoleh pengrajin opak ketan di
Kelurahan Kotabaru Kecamatan

Cibereum pada agroindustri opak ketan per satu kali proses produksi adalah Rp 607.506,-.

3. Kontribusi pendapatan rata-rata responden dari agroindustri opak ketan adalah 78,02\% (Rp 4.860.049,-).

4. Agrobisnis opak ketan memberikan kontribusi yang besar terhadap pendapatan keluarga perajin, sehingga usaha ini layak untuk dijalankan dan dikembangkan terlebih lagi jika adanya penambahan variasi rasa, menambah jumlah pegawai serta memperluas target market sehingga dapat meningkatkan profit bagi usaha opak ketan.

\section{Saran}

Berdasarkan kesimpulan, maka disarankan agar kegiatan agroindustri opak ketan di Kelurahan Kotabaru Kecamatan Cibereum dipertahankan dan volume usahanya serta sumber daya manusia semakin ditingkatkan, sehingga usaha agroindustri tetap bertahan dan berkembang. Selain itu, karena banyaknya kompetitor yang bergerak dibidang usaha yang sama, sehingga perlu adanya strategistrategi bisnis yang harus dilakukan dalam menghadapi persaingan secara kompetitif.

\section{DAFTAR PUSTAKA}

Aan Komariah, Djam'an Satori, 2011, Metode Penelitian Kualitatif, Bandung, Alfabeta 
Achmad Djaeni Sediaoetama: Ilmu Gizi, (1989), Penerbit Dian Rakyat, Jakarta

Ahmad. 2011. Analaisis Usaha Tani Padi Jenis Padi Ketan Putih. Skripsi. Fakultas Ekonomi dan Mnajaemen Institut Pertanian Bogor.

Alinna, Listyani, Zubaidah, Elok (2015). Formulasi Opak Bekatul Padi (Kajian Penambahan Bekatul dsan Proporsi Tepung Ketan Putih:Terigu). FTP: Universitas Brawijaya

Andistrian, Andri. 2014. Kajian Karakteristik Sensoris dan Fisikokimia Opak Ketan (oryza sativa glutinosa) yang Difortifikasi dengan Kacang Hijau. Universitas Sebelas Maret.

Arikunto, Suharsimi. 2006. Prosedur Penelitian Suatu Pendekatan Praktik. Rineka Cipta. Jakarta.

C. Muslim, dan C.R. Adawiyah. 2011. Panel Petani Nasional (Patanas): Dinamika Indikator Pembangunan Pertanian dan Perdesaan di Wilayah Agroekosistem Lahan Kering Berbasis Sayuran dan Palawija. Laporan Penelitian. Pusat Penelitian Sosial Ekonomi dan Kebijakan Pertanian. Bogor

Dinas Perindustrian, Perdagangan, Koperasi dan UMKM Kota Tasikmalaya. 2019. Data Sentra Industri Kecil dan Menengah Opak Kelapa 2019. Tasikmalaya

El Hadi, R. M., Tripiawan, W., \& Saedudin, R. (2017). Implementasi Alat Cetak Mekanis Opak Ketan Guna Meningkatkan Produktivitas (Studi Kasus: IKM Opak Ketan, Sumedang). Prosiding SNTI dan SATELIT 2017 (pp. C103-107).

Godam, 2012. Isi Kandungan Gizi GelatinKomposisi Nutrisi Bahan Makanan.

Husodo. 2009. Pertanian Mandiri. Penebar Swadaya. Jakarta.

Inding. 2018. Rentabilitas dan Penyerapan Tenaga Kerja Agroindustri Tahu Bulat serta Kontribusinya Terhadap Pendapatan Total Pengrajin di Desa Muktisari
Kecamatan Cipaku Kabupaten Ciamis. Fakultas Pertanian Universitas Galuh Ciamis. Jurnal.

Irfan. 2015. Kontribusi Penerimaan Usaha Gula Kelapa Terhadap Penerimaan Total Keluarga Perajin. Universitas Galuh Ciamis. Jurnal.

Mulyadi, (2015), Akuntansi Biaya Cetakan Ketigabelas, Yogyakarta: Unit Penerbit Dan Percetakan Sekolah Tinggi Ilmu Manajemen YKPN.

Rahim, A. Dan Hastuti. 2007. Ekonomika Pertanian (Pengantar, Teori, dan Kasus).Penebar Swadaya. Jakarta.

Purnomo, E. 2005. Tingkat Pendapatan dan Kesejahteraan Peserta Program Perhutanan Sosial Masyarakat Desa Cibingbin Kabupaten Kuningan Jawa Barat. UNWIM. Bandung

Sugiyono. 2014.Metode Penelitian Bisnis. Bandung : Alfabeta.

Suratiyah, K. 2006.Ilmu Usahatani. Jakarta: Penebar Swadaya. 2015. Ilmu Usahatani Edisi Revisi. Jakarta: Penerbit Swadaya

Wibowo (2011). Manajemen Kinerja. Jakarta: PT. Raja Grafindo Persada

Wahyono, Budi.2017.”Analisis Faktor-Faktor Yang Mempengaruhi Pendapatan Pedagang di Pasar Bantul kabupaten Bantul".Jurnal Pendidikan Ekonomi. No. 4, Vol. 6

Walgito, Bimo. (2010). Bimbingan dan Konseling Studi \& Karir. Yogjakarta: Andi

Yulida ,Roza.2010. Kontribusi Wanita Pekerja Agroindustri Nenas Terhadap Pendapatan Rumah Tangga Di Desa Kuwalu Nenas Kecamatan Kuwalu Kabupaten Kampar. Fakultas Pertanian Universitas Riau. Jurnal.

Zulfikar, 2017. Kontribusi pendapatan Agroindustri Gula Kelapa Terhadap Pendapatan Total Keluarga Pengarajin. Universitas Galuh. Jurnal 